\begin{tabular}{|c|c|c|}
\hline||$\left\{\left.||\right|_{\text {ge: http:/jusami.batan.go.id }}\right.$ & Jurnal Sains Materi Indonesia & $\begin{array}{l}\text { Akreditasi LIPI } \\
\text { No.: 602/AU3/P2MI-LIPI/03/2015 } \\
\text { Tanggal } 15 \text { April } 2015 \\
\text { ISSN : 1411-1098 }\end{array}$ \\
\hline
\end{tabular}

\title{
EFEK PENAMBAHAN ASAM FENILFOSPONAT-SENG, TALK DAN TRIASETIN TERHADAP LAJU KRISTALISASI POLIASAM LAKTAT
}

\section{Lisman Suryanegara ${ }^{1}$, Putri Yuliansih ${ }^{2}$, Firda Aulya Syamani ${ }^{1}$, Raden Permana Budi Laksana $^{1}$, Subyakto ${ }^{1}$, Zaenal Abidin ${ }^{2}$, Nanang Masruchin ${ }^{1}$ dan Yuliati Indrayani ${ }^{3}$}

\author{
${ }^{1}$ Pusat Penelitian Biomaterial - LIPI \\ Jl. Raya Bogor Km.46, Cibinong Bogor 16911 \\ ${ }^{2}$ Departemen Kimia, FMIPA - IPB \\ Jl. Meranti, Kampus IPB Dramaga, Bogor 16680 \\ ${ }^{3}$ Fakultas Kehutanan - Universitas Tanjungpura \\ Jl. Prof. Hadari Nawawi, Pontianak 78121 \\ E-mail: l_suryanegara@yahoo.co.id
}

\begin{abstract}
ABSTRAK
EFEK PENAMBAHAN ASAM FENILFOSPONAT-SENG, TALK DAN TRIASETIN TERHADAP LAJU KRISTALISASI POLIASAM LAKTAT. Dalam aplikasi industri, salah satu kekurangan poli asam laktat (PLA) adalah kristalisasi yang lambat, sehingga meneyebabkan waktu yang lebih lama untuk mengolah $P L A$ dibandingkan dengan polimer konvensional seperti polipropilen. Penelitian ini mengevaluasi pengaruh penambahan pengisi atau aditif terhadap laju kristalisasi PLA. PLA dilarutkan dalam diklorometana $(D C M)$ dan dicampur dengan nucleating agent (seng asam fenilfosfonat atau talk) atau pelunak (triasetin) pada konsentrasi yang berbeda diikuti dengan pengeringan pada suhu kamar selama 24 jam dan pengeringan oven selama 2 jam pada suhu $80^{\circ} \mathrm{C}$. Campuran kering PLA ditempa panas pada $180^{\circ} \mathrm{C}$ selama 10 menit. Differential Scanning Calorimetry $(D S C)$ dilakukan untuk mengevaluasi tingkat kristalisasi. Hasil studi menunjukkan bahwa penambahan pengisi atau aditif mempercepat proses kristalisasi PLA. Asam seng fenilfosponat $(P P A-\mathrm{Zn})$ adalah pengisi yang paling efektif untuk mempercepat laju kristalisasi $P L A$.
\end{abstract}

Kata kunci: Poli asam laktat, Laju kristalisasi, Mucleating agent, Pemlastis

\begin{abstract}
THE EFFECT OF PHENILPHOSPHONIC ACID-ZINK, TALC OR TRIACETINE ADDITION ON THE CRYSTALLIZATION RATE OF POLYLACTIC ACID . In industrial application, one of the drawbacks of polylactic acid (PLA) is a slow crystalization, resulted in longer time to process PLA compared to conventional polymer such as polypropylene. This study evaluates the effect of fillers or additives addition on the crystalitation rate of PLA. PLA was dissolved in an organic solvent dichloromethane (DCM) and mixed with nucleating agent (phenylphosphonic acid zinc or talc) or plasticizer (triacetine) at different concentration followed by drying at room temperature for overnight and oven drying for 2 hours at $80^{\circ} \mathrm{C}$. The dried mixture of PLA was hot pressed at 180 ÚC for $10 \mathrm{~min}$. Differential Scanning Calorimetry (DSC) was performed to evaluate crystallization rates. The results showed that the addition of filler or additive accelerates the crystallization process of PLA. Phenylphosponic acid zinc (PPA-Zn) is the most effective filler to acceleate crystallization of PLA.
\end{abstract}

Keywords: Polylactic acid, Crystallization rate, Nucleating agent, Plasticizer 


\section{PENDAHULUAN}

Selama kurang lebih dari satu dekade, plastik telah digunakan untuk membuat berbagai macam produk, seperti alat-alat elektronik dan suku cadang kendaraan bermotor. Hal ini karena kemudahanya untuk diproses, produktivitas yang tinggi, dan pengurangan biaya produksi yang cukup besar. Sebagian besar plastik yang digunakan adalah polipropilen dan polietilen yang merupakan polimer berbasis minyak bumi.

Kebutuhan dunia industri akan material yang mudah dikembangkan dan diperoleh serta ramah lingkungan menyebabkan munculnya berbagai penelitian dalam dua dekade terakhir ini. Penelitian ini mengarah pada suatu material yang berbasis pada sumber daya hayati dan bahan-bahan pertanian. Hal ini didukung pula oleh meningkatnya harga bahan-bahan yang berasal dari minyak bumi tiap tahunnya dan sumber minyak bumi yang semakin menipis. Beberapa biopolimer yang dikembangkan oleh peneliti adalah poliasam laktat (PLA), polibutilen suksinat $(P B S)$, polihidroksi butirat $(P H B)$ dan polihidroksi butirat-polihidroksi valerat $(P H B V)$.

Berdasarkan penelitian yang telah dilakukan sebelumnya, diantara biopolimer lain seperti $P B H$ [2], $P B S$ [3], dan $P H B V$ [2], PLA [4] memiliki potensi yang besar untuk menggantikan polimer konvensional seperti polipropilen [5] dan polistiren [6] karena memiliki Modulus Young dan kekuatan tarik yang tinggi (Tabel 1). PLA (Gambar 1) adalah polimer serba guna yang terbuat dari bahan baku pertanian terbarukan yang difermentasi untuk memperoleh asam laktat. Asam laktat yang akan diubah menjadi poli asam laktat dan dapat diaplikasikan pada industri polimer yang ramah lingkungan (biodegradable polymer). Asam laktat yang diperoleh dengan cara fermentasi ini berasal dari bahan baku yang mengandung glukosa, sukrosa, maltosa, dan laktosa [7].

Tabel 1. Sifat mekanik pada beberapa biopolimer, polipropilen, dan polistiren [1].

\begin{tabular}{lccc}
\multicolumn{1}{c}{ Bahan } & $\begin{array}{c}\text { ModulusYoung } \\
(\mathrm{Gpa})\end{array}$ & $\begin{array}{c}\text { Kekuatan Tarik } \\
(\mathrm{Mpa})\end{array}$ & $\begin{array}{c}\text { Ketegangan } \\
(\%)\end{array}$ \\
\hline PBS & 0,5 & 35 & 15 \\
PHBV & 1,5 & 30 & 12 \\
PHB & 3,0 & 40 & 4 \\
PLA & 3,6 & 50 & 2,4 \\
Polipropilen & 1,7 & 38 & 40 \\
Polistiren & 3,5 & 40 & 3 \\
\hline
\end{tabular}

PLA memiliki banyak kelebihan diantaranya dapat diproses mirip dengan poliolefin [4], ramah lingkungan, dan memiliki potensi besar untuk menggantikan polimer yang berbasis pada minyak bumi [8]. Walaupun demikian, dalam aplikasi industri PLA memiliki kelemahan, khususnya pada kecepatan kristalisasinya yang lambat. Banyak usaha telah dilakukan untuk meningkatkan kecepatan kristalisasinya. Dua pendekatan telah dianggap dapat meningkatkan kecepatan kristalisasi $P L A$. Pertama, PLA ditambahkan dengan nucleating agent yang akan menurunkan surface energy barrier terhadap nukleasi sehingga dapat memulai kristalisasi pada suhu yang lebih tinggi selama pendinginan [9]. Penelitian sebelumnya telah menunjukkan bahwa talk [9] dan phenylphosphonic acid zinc (PPA-Zn) (Gambar 2) [10] dapat digunakan sebagai nucleating agent.<smiles>CC(O)C(=O)OC(C)C(=O)OC(C)C(=O)O</smiles>

Gambar 1. Struktur PLA

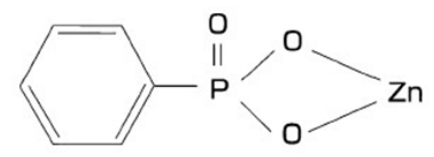

Gambar 2. Struktur PPA-Zn [10]

Cara kedua, PLA ditambahkan dengan plasticizer yang bertujuan meningkatkan mobilitas rantai polimer dan tingkat kristalisasi dengan mengurangi energi yang dibutuhkan selama kristalisasi [9]. Hasil penelitian sebelumnya bahwa triasetin dapat digunakan sebagai pemlastis untuk meningkatkan kecepatan kristalisasi PLA [11]. Penelitian ini bertujuan menentukan filler terbaik pada $P L A$ untuk meningkatkan kecepatan kristalisasi PLA dengan metode Differential Scanning Calorimetry (DSC).

\section{METODE PERCOBAAN}

\section{Bahan dan Alat}

Bahan-bahan yang digunakan adalah PLA semicrystalline 3001D yang dipasok oleh Nature-Works, $P P A-$ Zn yang dipasok oleh Nissan Chemical Industries, Ltd., Japan, talk yang dipasok oleh PT Brataco, dan glicerol triacetate (triasetin) dipasok oleh Wako. Pelarut PLA yang digunakan adalah diklorometana $(D C M)$ yang dipasok oleh Merck. Alat-alat yang digunakan dalam praktik lapangan ini terdiri atas hot plate, magnetic stirrer, oven, hot press, dan DSC Perkin-Elmer 4000 untuk melihat kecepatan kristalisasi.

\section{Cara Kerja}

\section{Persiapan Sampel}

$P L A$ dengan bobot $5 \mathrm{~g}$ ditimbang dan dilarutkan dalam $40 \mathrm{~mL} D C M$ dengan menggunakan magnetic stirer. PLA yang sudah larut sempurna kemudian dicetak pada nampan dan dikeringudarakan selama semalam dalam ruang asam. PLA yang sudah kering kemudian dipanaskan dalam oven selama 2 jam pada suhu $80{ }^{\circ} \mathrm{C}$. 
Efek Penambahan Asam Fenilfosponat-Seng, Talk dan Triasetin Terhadap Laju Kristalisasi Poliasam Laktat (Lisman Suryanegara)

Tahap selanjutnya, PLA di-hotpress pada suhu $180{ }^{\circ} \mathrm{C}$ selama 10 menit. Hasil press ini disebut dengan neat PLA. Hal yang sama juga di-lakukan pada komposit PLA/PPA-Zn, PLA/talk, dan PLA/triasetin. Filler dimasukkan ketika $P L A$ sudah larut dalam $D C M$. Pencampuran PLA dengan filler dilakukan sampai homogen. Konsentrasi filler yang digunakan yaitu $0,5 \% ; 1 \%$ dan $2 \%$ untuk nucleating agent (PPA-Zn dan talk) dan $5 \% ; 10 \%$; dan $20 \%$ untuk plasticizer (triasetin)

\section{Differential Scanning Calorimetry}

Pengukuran dengan DSC ini dilakukan dalam satu kondisi, yaitu non-isothermal. Sebanyak $\pm 5 \mathrm{mg}$ sampel ditimbang dan dimasukkan ke pans yang telah tersedia. Lalu, dimasukkan ke dalam $D S C$ dan dijaga pada suhu $0{ }^{\circ} \mathrm{C}$ selama 10 menit untuk pengondisian awal. Sampel dipanaskan dari $0{ }^{\circ} \mathrm{C}$ hingga $200{ }^{\circ} \mathrm{C}$ dengan kecepatan $5{ }^{\circ} \mathrm{C} /$ menit dan dijaga pada suhu $200{ }^{\circ} \mathrm{C}$ selama 3 menit untuk memastikan polimer telah meleleh semua. Selanjutnya, sampel didinginkan dari $200{ }^{\circ} \mathrm{C}$ ke $0{ }^{\circ} \mathrm{C}$ dengan kecepatan yang sama. Gas $\mathrm{N}_{2}$ yang digunakan sebanyak $20 \mathrm{~mL} / \mathrm{menit}$. Suhu transisi gelas $(\mathrm{Tg})$, suhu kristalisasi (Tc), suhu leleh (Tm), dan entalpi peleburan $(\Delta \mathrm{Hm})$ ditentukan dari scan pemanasan sampel.

\section{HASIL DAN PEMBAHASAN}

Kecepatan kristalisasi dan derajat kristalinitas pada PLA adalah beberapa parameter penting dari sudut pandang industri yang mempengaruhi produktivitas injection molding dan kinerja produk yang dibentuk [10]. Kecepatan kristalisasi pada PLA ini dapat ditingkatkan dengan menambahkan nucleating agent dan plasticizer.

PLA yang digunakan adalah semi kristalin. Oleh sebab itu, termogram PLA yang diukur dengan kondisi tertentu pada prosedur di atas menghasilkan puncak transisi gelas (Tg), kristalisasi (Tc), dan peleburan (Tm) [12] Hal ini berbeda dengan PLA amorf yang hanya menghasilkan puncak Tg [4]. Pada transisi gelas terjadi perubahan sifat mekanik dari polimer elastis menjadi polimer yang rapuh (brittle) akibat perubahan mobilitas rantai. Di atas suhu Tg, rantai polimer memiliki mobilitas yang tinggi. Pada beberapa suhu diatas $\mathrm{Tg}$, rantai memiliki energi yang cukup untuk menjalani kristalisasi. Kristalisasi adalah proses eksotermik (panas dilepaskan ke lingkungan), sedangkan pelelehan merupakan proses endotermik (membutuhkan penyerapan panas) (Gambar 3).

Penambahan agent penukleasi pada $P L A$ bertujuan menurunkan surface energy barier sehingga dapat memulai kristalisasi dengan lebih cepat. Ketika polimer semikristal mengkristal dari lelehan (biasanya selama fase pendinginan dari proses), terbentuk kompleks makrostruktur yang disebut spherulites. Pengaruh penambahan filler berupa microcrystalline

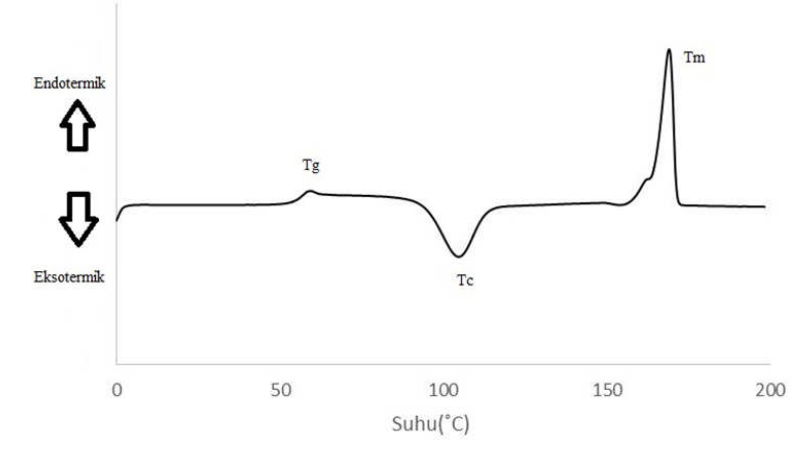

Gambar 3. Termogram DSC neat PLA.

cellulose (MCC) pada proses kristalisasi PLA telah dipelajari peneliti sebelumnya [4]. Adanya penambahan MCC kedalam PLA dapat berperan sebagai nucleating agent yang bisa dijadikan tempat tumbuhnya spherulite. Dalam penelitian ini nucleating agent yang digunakan adalah $P P A-\mathrm{Zn}$ dan talk. $P P A-\mathrm{Zn}$ atau dikenal pula dengan nama PPZn [1] memiliki enam koordinat atom Zn yang terikat pada dua oksigen fosfonat.

Hasil analisis DSC antara neat PLA dengan komposit $P L A / P P A-Z n$ dengan berbagai konsentrasi (Gambar 4) menunjukkan bahwa penambahan $P P A-Z n$ pada $P L A$ menurunkan Tg dan Tc. Hal ini menunjukkan bahwa proses kristalisasi menjadi lebih cepat. Selain itu, pada suhu kristalisasi pendinginan (Tabel 2), penambahan PPA-Zn pada PLA menyebabkan suhu kristalisasi dimulai pada suhu yang lebih tinggi. Hal ini sesuai dengan hasil penelitian [9] yang mengindikasikan bahwa penambahan nucleating agent menyebabkan proses kristalisasi berjalan lebih cepat dari pada polimer murninya. Semakin tinggi konsentrasi $P P A-\mathrm{Zn}$ yang ditambahkan, kecepatan kristalisasinya semakin cepat. Berdasarkan penelitian sebelumnya bahwa konsentrasi optimum agent penukleasi yang ditambahkan ke dalam PLA sebesar $1 \%$ (w/w) [9]. Hal ini berlaku juga untuk talk (Gambar 5).

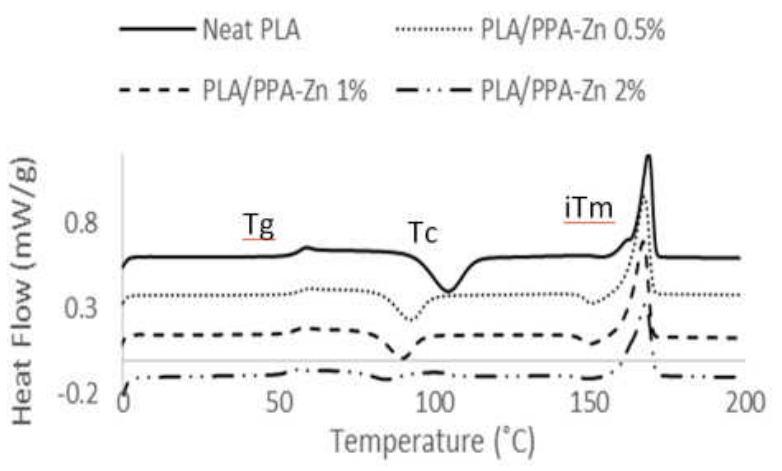

Gambar 4. Termogram DSC neat PLA dan PLA/PPA-Zn pada bebagai konsentrasi.

Perbedaan dari keduanya antara PPA-Zn dan talk adalah terletak pada kemampuan dalam menambah kecepatan kristalisasi PLA. Berdasarkan dari Tabel 2, 
Tabel 2. Data termal neat PLA dan komposit PLA pada berbagai konsentrasi

\begin{tabular}{lcccc}
\hline \multicolumn{1}{c}{ Komponen } & $\begin{array}{c}\text { Suhu Transisi } \\
\text { Gelas } \\
\left({ }^{\circ} \mathrm{C}\right)\end{array}$ & $\begin{array}{c}\text { Suhu Kristalisasi } \\
\text { Peleburan } \\
\left({ }^{\circ} \mathrm{C}\right)\end{array}$ & $\begin{array}{c}\text { Suhu Lebur } \\
\left({ }^{\circ} \mathrm{C}\right)\end{array}$ & $\begin{array}{c}\text { Suhu Kristalisasi } \\
\text { Pendinginan } \\
\left({ }^{\circ} \mathrm{C}\right)\end{array}$ \\
\hline Neat PLA & 55,24 & 104,59 & 168,99 & 100,31 \\
Nucleating agent & & & & \\
0,5\%(w/w) PPA-Zn & 56,79 & 92,51 & 167,74 & 128,58 \\
1\%(w/w) PPA-Zn & 55,27 & 89,92 & 167,25 & 129,15 \\
2\%(w/w) PPA-Zn & 52,20 & 84,64 & 168,08 & 129,75 \\
0,5\%(w/w) Talk & 52,66 & 100,35 & 168,64 & 102,99 \\
$1 \%(w / w)$ Talk & 51,69 & 102,41 & 168,34 & 102,64 \\
$2 \%($ w/w) Talk & 51,58 & 99,51 & 168,25 & 107,82 \\
Plasticizer & & & & \\
$5 \%(w / w)$ Triasetin & 44,39 & 94,58 & 164,93 & 99,98 \\
$10 \%(w / w)$ Triasetin & 36,45 & 87,51 & 162,02 & 92,31 \\
20\%(w/w) Triasetin & 25,44 & 68,92 & 157,95 & 98,38 \\
\hline
\end{tabular}

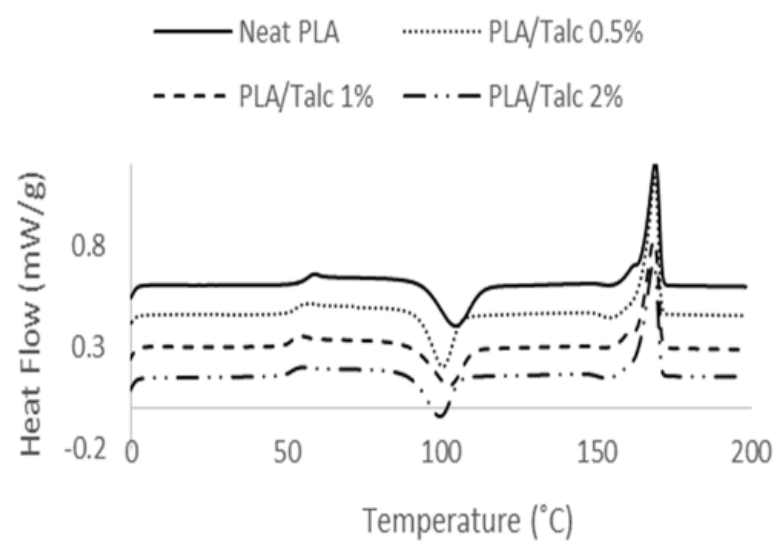

Gambar 5. Termogram DSC neat PLA dan PLA/talk pada beberapa konsentrasi.

Penambahan zat aditif pada PLA dapat mempengaruhi nilai $\mathrm{Tg}$ dan nilai Tc. Nilai Tg dari $P L A$ turun ketika ditambahkan nucleating agent dan turun drastis saat ditambahkan plasticizer. Penurunan Tg berimplikasi pada kekuatan dari komposit yang berkurang drastis saat menerima beban pada suhu di atas Tg. Sedangkan proses kristalisasi dapat dipelajari dari nilai Tc. Penurunan nilai Tc mengindikasikan kristalisasi berlangsung lebih cepat, hal ini ditunjukkan ketika penambahan $P P A-Z n$ dapat menurunkan Tc yang jumlah penurunannya sebanding dengan penambahan konsentrasi $P P A-Z n$. Fenomena penurunan Tc juga terjadi pada penambahan talk dan triasetin yang mengindikasikan terjadinya percepatan proses kristalisasi.

Penambahan PPA-Zn dan talk pada PLA tidak mengubah nilai titik lebur. Hal ini berbeda ketika ditambahkan plasticizer, dimana titik leburnya turun drastis. Hal ini dikarenakan adanya plasticizer hingga memudahkan pergerakan rantai polimer. Pada saat pendinginan, nilai suhu kristalisasi pendinginan dari $P L A$ yang ditambahkan $P P A-Z n$ suhunya meningkat Hal tersebut mengindikasikan proses kristalisasi berlangsung lebih cepat dibandingkan PLA murni. Sedangkan penambahan talk dan plasticizer terhadap PLA tidak menyebabkan perubahan Tc yang signifikan.
Hal tersebut sejalan dengan hasil Tc yang mengindikasikan bahwa penambahan PPA-Zn sangat efektif dalam mempercepat proses kristalisasi PLA walaupun dalam jumlah yang relatif sedikit dibandingkan dengan konsentrasi plasticizer. Dari Tabel 2. menunjukan efisiensi dan efektifitas bahan aditif berupa nucleating agent dan plasticizer dalam mempercepat proses kristalisasi. Penurunan suhu masih sebanding dengan penambahan konsetrasi aditif. Karena tujuan dalam penelitian ini adalah untuk mencari zat aditif yang dapat mempercepat proses kristaliasasi.

Penambahan pemlastis pada PLA dapat menurunkan $\mathrm{Tg}$ akibat adanya ruang untuk mobilitas rantai polimer sehingga dapat meningkatkan kecepatan kristalisasinya [11]. Prinsip kerjanya adalah dispersi molekul pemlastis ke dalam fase polimer. Apabila pemlastis mempunyai gaya interaksi ke dalam fase polimer, proses dispersi akan berlangsung dalam skala molekul dan terbentuk larutan polimer-pemlastis, keadaan ini disebut kompatibel. Interaksi antara polimer-pemlastis dipengaruhi oleh sifat afinitas kedua komponen. Apabila afinitas polimer-pemlastis kecil, akan terjadi plastisasi antara struktur, artinya molekul pemlastis hanya terdistribusi di antara struktur molekul. Sedangkan kalau afinitas polimer pemlastis tinggi, maka molekul pemlastis akan terdifusi ke dalam bundel, sehingga molekul pemlastis akan berada di antara rantai polimer dan mempengaruhi mobilitas rantai.

Pemlastis yang digunakan adalah triasetin dengan nama glycerol triacetate. Hasil analisis DSC menunjukkan bahwa penambahan triasetin pada $P L A$ dapat meningkatkan kecepatan kristalisasi $P L A$. Indikasi ini ditunjukan dari termogram yang dihasilkan (Gambar 6) dan data termal yang diperoleh. Semakin besar konsentrasi triasetin yang ditambahkan, semakin meningkat kecepatan kristalisasinya. Hasil penelitian sebelumnya menunjukkan bahwa konsentrasi optimum triasetin yang ditambahkan adalah $10 \%(w / w)$ [7]. Penambahan triasetin ke dalam $P L A$ untuk meningkatkan kecepatan kristalisasi kurang efektif dibandingkan 
Efek Penambahan Asam Fenilfosponat-Seng, Talk dan Triasetin Terhadap Laju Kristalisasi Poliasam Laktat (Lisman Suryanegara)

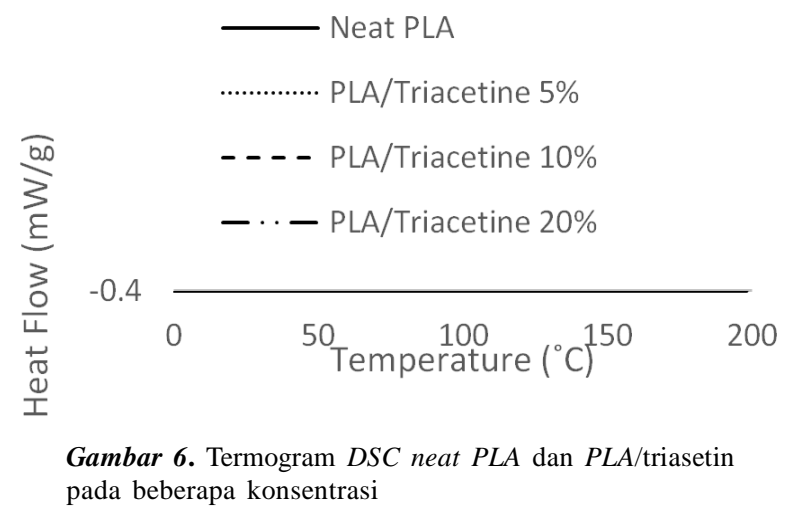

dengan talk dan PPA-Zn. Hal ini dikarenakan PPA-Zn merupakan kombinasi dari asam fosfonat berperan sebagai plasticizer dalam menurunkan Tg dan seng yang dapat berperan sebagai partikel anorganik untuk memicu tumbuhnya spherulite.

Asam fosfonat dapat menjadi plasticizer pada PLA dengan cara meningkatkan mobilitas molekul PLA, sehingga dapat meningkatkan laju kristalisasi, yang memungkinkan PLA untuk mengkristal ke tingkat yang lebih tinggi selama pendinginan [11]. Sedangkan seng dapat menjadi pemicu tumbuhnya spherulite karena material anorganik ini dapat mempercepat terbentuknya larutan jenuh pada polimer. Spherulite dapat tumbuh lebih cepat dalam keadaan jenuh yang tinggi. Hal ini menunjukkan spherulite tumbuh di bawah kondisi rasio kejenuhan yang lebih tinggi, sehingga membuat spherulite yang terbentuk pada tahap awal lebih stabil [13].

\section{KESIMPULAN}

Hasil penelitian menunjukkan bahwa penambahan nucleating agent dan plasticizer berupa $P P A-Z n$, talk dan triasetin, terbukti dapat mempercepat proses kristalisasi pada PLA. Kecepatan kristalisasi yang dihasilkan berbanding lurus dengan konsentrasi zat aditif yang ditambahkan. Dari ketiga bahan tersebut, penambahan $P P A-Z n$ merupakan aditif yang efektif dan efisien dalam mempercepat proses kristalisasi.

\section{UCAPAN TERIMAKASIH}

Kegiatan penelitian ini dibiayai oleh LIPI, Kemenristek melalui Insinas dan Satreps Biorefinery.

\section{DAFTAR ACUAN}

[1]. Y. Chen, E. Chen, and T. Wu. "Organically Modified Layered Zinc Phenylphosphonate Reinforced Stereocomplex-Type Poly (Lactic Acid) Nanocomposites with Highly Enhanced Mechanical Properties and Degradability." J. Mater. Sci., vol. 50, Issue 23, pp. 7770-7778 2015.
[2]. N. M. Barkoula, S. K. Garkhail, and T. Peijs. "Biodegradable Composites Based on Flax / Polyhydroxybutyrate And Its Copolymer with Hydroxyvalerate." Ind. Crops Prod., vol. 31, pp. 34-42, 2010.

[3]. S. Lee, D. Cho, W. H. Park, S. G. Lee, S. O. Han, and L. T. Drzal. "Novel Silk/Poly (Butylene Succinate) Biocomposites/ : The Effect of Short Fibre Content on Their Mechanical and Thermal Properties." Compos. Sci. Technol., vol. 65, pp. 647-657, 2005.

[4]. A. P. Mathew, K. Oksman, and M. Sain.'The Effect of Morphology and Chemical Characteristics of Cellulose Reinforcements on the Crystallinity of Polylactic Acid." J. Appl. Polym. Sci., vol. 101, pp. 300-310, 2006.

[5]. G. Bogoeva-Gaceva, M. Avella, M. Malinconico, A. Buzarovska, A. Grozdanov, G. Gentile, and M. E. Errico. "Natural Fiber Eco-Composites." Polym. Compos., vol. 28, pp. 98-107, 2007.

[6]. S. Siengchin. "Processing, Structure, and Mechanical Properties of Alumina-Nanofilled Polystyrene composites." Mech. Compos. Mater., vol. 46, no. 4, pp. 443-450, 2010.

[7]. S. Purnavita, H. Sriyana, and S. Hartini. "Rekayasa Proses Produksi Asam Laktat dari Limbah Ampas Pati Aren Sebagai Bahan Baku Poli Asam Laktat." Momentum, vol. 10, no. 1, pp. 14-18, 2009.

[8]. Y. Hu, M. Rogunova, V. Topolkaraev, A. Hiltner, and E. Baer. "Aging of Poly (Lactide)/Poly (Ethylene Glycol) Blends . Part 1. Poly (Lactide) with Low Stereoregularity." Polym., vol. 44, pp. 5701-5710, 2003.

[9]. H. Li and M. A. Huneault. "Effect of Nucleation and Plasticization on The Crystallization of Poly (Lactic Acid )." Polym. 48, vol. 48, pp. 6855-6866, 2007.

[10]. L. Suryanegara and A. Norio. "Thermo-Mechanical Properties of Microfibrillated Cellulose-Reinforced Partially Crystallized PLA Composites." Cellulose, vol. 17, pp. 771-778, 2010.

[11]. N. Ljungberg and B. Wesslen. "The Effects of Plasticizers on the Dynamic Mechanical and Thermal Properties of Poly (Lactic Acid)." J. Appl. Polym. Sci., vol. 86, pp. 1227-1234, 2002.

[12]. X. Cao, A. Mohamed, S. H. Gordon, J. L. Willett, and D. J. Sessa. "DSC Study Of Biodegradable Poly (Lactic Acid) and Poly (Hydroxy Ester Ether) Blends." Thermochim. Acta, vol. 406, pp. 115-127, 2003.

[13]. N. Wada, K. Yamashita, and T. Umegaki. "Effects of Divalent Cations Upon Nucleation, Growth and Transformation of Calcium Carbonate Polymorphs Under Conditions of Double Diffusion." J. Cryst. Growth, vol. 148, pp. 297-304, 1995. 